\title{
Analyzing Roll Calls with Perfect Spatial Voting:
}

\author{
France 1946-1958
}

\section{Howard Rosenthal}

Roger Williams Straus Professor of Social Sciences, Professor of Politics

Princeton University

Princeton NJ, 08544

E-mail: rosentha@princeton.edu

And (Fall 2003):

Distinguished Visiting Professor of Economics and Politics

Department of Economics

Brown University

Box B

64 Waterman Street

Providence, RI 02912

\section{Erik Voeten (corresponding author)}

Assistant Professor of Political Science and International Affairs

The George Washington University

Funger Hall 514, 2201 G Street, NW

Washington DC 20052

E-mail: voeten@gwu.edu 


\section{Acknowledgements}

This work was supported by National Science Foundation (NSF) grant \#973053. Any opinions, findings, and conclusions or recommendations in this work are those of the authors and do not necessarily reflect the views of the NSF. We thank three anonymous referees, discussants and participants at the 2001 annual meeting of the American Political Science Association in San Francisco, the annual meeting of the Public Choice Society, San Diego, CA, March 22-24, 2002, and seminar participants at Berkeley, particularly Robert Powell, for comments. A very special thanks to Keith Poole for his counsel and programs.

Keywords: spatial models, roll call voting, W-NOMINATE, French Fourth Republic, nonparametric methods 


\begin{abstract}
A recent methodological advance in legislative roll-call analysis is especially relevant to the study of legislative behavior outside the setting of the United States Congress. We argue that Poole’s (2000) optimal classification method for roll call analysis is preferable to parametric methods for studying many legislatures. This is because the nature of party discipline, nearperfect spatial voting, and parliamentary institutions that provide incentives for strategic behavior lead to severe violations of the error assumptions underlying parametric methods. The robustness of the non-parametric method to the stochastic nature of the data makes it an ideal candidate for studying strategic behavior in legislatures. We illustrate these points with an analysis of data from the French Fourth Republic (1946-1958).
\end{abstract}


This paper argues that Poole's (2000) new optimal classification method for roll call analysis is preferable to parametric methods for studying many legislatures outside of the United States Congress. The reason is that assumptions about errors in voting that underlie W-NOMINATE and other parametric methods, generally developed for and tested on congressional roll call data, are likely to be inappropriate in most legislative settings. We support this point through an analysis of data from the three legislatures of the French National Assembly in the short-lived and not lamented Fourth Republic (1946-58). The National Assembly had at least five characteristics that make the application of parameteric methods problematic: variation in discipline across parties, unstable party memberships, proxy voting, near perfect twodimensional spatial voting, and parliamentary institutions that provide incentives for strategic voting. Our analyses demonstrate that Poole's non-parametric method allows us to analyze legislative behavior within the theoretically attractive spatial framework when W-NOMINATE fails. Moreover, we show that the method's robustness to the stochastic nature of the data makes it an excellent tool to study strategic behavior by legislators.

Our findings are relevant to the increasing number of applications of modern roll call methods to legislative settings where both recorded votes are common and party-line voting is not absolute. This includes supranational settings such as the European Parliament (Hix 2001; Noury 2002; Hix, Noury and Roland 2002) and the United Nations General Assembly (Voeten 2000); historical episodes such as the Confederate legislature (Jenkins 1999) and the repeal of the Corn Laws in $19^{\text {th }}$ century Britain (Schonhardt-Bailey 2003); legislatures in established democracies such as Australia (Jackman 2001); and parliaments in emerging democracies including the Czech republic (Noury and Mielcova 1997), Poland (Mercik and Mazurkiewicz 1997), Russia (Kiewiet and Myagkov 1996), and various Latin American countries (Londregan 
2000, Carey 2003, Desposato 2003, Morgenstern 2003). While the French National Assembly

was, like any legislature, in some ways unique, many of the above-mentioned legislatures share important characteristics with the National Assembly and differ in important ways from Congress. This is particularly true with regard to variations in party discipline and incentives for strategic behavior provided by the vote of confidence procedure.

\section{Methodological Issues}

Modern roll call analysis has undergone an increasingly sophisticated methodological development [Poole and Rosenthal 1985, 1991, 1997; Heckman and Snyder 1997; Londregan 1999; Poole 2001; Clinton and Meirowitz 2001, and Clinton, Jackman, and Rivers 2001]. The maintained hypothesis of these models is that roll call voting fits a probabilistic spatial model of voting. ${ }^{1}$ Points in a common space represent both the Yea and Nay outcomes on each roll call and the legislator's bliss point. A legislator is more likely to vote Yea on a roll call if the legislator's point is closer to the Yea point than to the Nay point. The vote is only more likely, not certain, because the votes are subject to error.

Parametric and stochastic models like the NOMINATE methods of Poole and Rosenthal, the Heckman-Snyder method, or the Bayesian methods developed by Clinton, Jackman, and Rivers recover metric information about legislator and roll-call characteristics by exploiting the essential assumption of the probabilistic spatial model that some errors are more likely than others. While the methods differ in their choice of distribution for the errors (logistic, uniform and normal respectively), they all rely on the assumption that errors are independent and

\footnotetext{
${ }^{1}$ We describe the methods informally and refer to the published literature for formal treatments. For a formal treatment of the probabilistic spatial model see Enelow and Hinich 1984.
} 
identically distributed (i.i.d.) across both legislators and roll calls. Moreover, just like in probit and logit, the ability to obtain precise parameter estimates depends heavily on the errors being relatively substantial. Violations of these basic error assumptions are likely to be more severe in legislatures other than Congress. The French National Assembly has five important characteristics which are likely to cause problems for parametric methods. Many other legislatures share at least some of these.

A first issue is party discipline. A large fraction of the deputies were members of a party that voted as a bloc, the Communists. As we move to the right in the political spectrum, we find the Socialists, only somewhat less disciplined than the Communists. Even the Christian Democrats (MRP) tended to mostly vote as a bloc. The other deputies, largely in the political center and right, were more freewheeling in their behavior. If some legislators are subject to greater party pressure than others, the assumption that errors are i.i.d. is almost surely violated. Moreover, the presence of fully disciplined parties effectively reduces the number of independent actors. This is likely a problem in most multi-party legislatures. Party discipline generally exceeds that observed in Congress. Fully disciplined parties are not unusual. Nevertheless, there commonly is considerable variation in the cohesion of parties within national parliaments (e.g. Janda 1980, chapter 11) and in the European Parliament (Hix, Noury and Roland 2003).

Second, changes in party affiliation were common in the Fourth Republic (Riker, 1959). As we document later in this paper, almost 20 percent of the deputies elected made at least one major change in party affiliation during the 12 years of the Republics. Party switching is rare in Congress but fairly widespread in several other countries including Brazil, Ecuador, Italy, Japan, Nepal, and the Philippines (Desposato 2003). If legislators do not alter their voting behavior as a consequence of their change in party affiliation, party switching obviously poses no problems for 
the spatial model. If, however, legislators switch from a more to a less disciplined party (or vice versa) and thus become subject to varying degrees of party pressure across roll calls, the error assumptions are violated. Moreover, party switching may result in ideal-point changes. ${ }^{2}$ In our estimation we address these problems by splitting up the voting records of party-switchers and estimating separate ideal points for each stint with a party.

Third, both discipline, making for more predictability, and vote trading, making for less, may have been influenced by the presence of proxy voting on most roll calls. Proxy voting is common practice in many legislative settings, but is not permitted in Congress, except in committees. Since it is highly likely that some legislators use proxy voting more frequently than others, i.i.d. assumptions are likely violated To be specific, if Martine gives her proxy to Pierre without any instructions as to how Pierre is to vote, any “error” that affects Pierre’s recorded vote is also likely to affect Martine’s.

Fourth, as we will demonstrate, voting behavior in the Fourth Republic almost perfectly fits a two-dimensional spatial model. Given that parameter estimates in parametric methods depend on the error being relatively substantial, applying the models to a strongly ideological, small error legislature will be problematical. As a result of near-perfect spatial voting in France, WNOMINATE tends to place legislator ideal points on the boundary of the unit hypersphere that defines the limits of the ideological space. This renders interpretation of the ideological space difficult. The fit of low-dimensional spatial models in legislatures outside of the U.S. generally

\footnotetext{
2 McCarty, Poole, and Rosenthal (2000) show that the rare party-switches in Congress are accompanied by substantial, significant shifts in ideological positions.
} 
exceeds the already impressive fit for Congress (Poole and Rosenthal 2001, table 2). Thus, we may expect similar problems to arise in other applications.

Fifth, although deputies typically voted in a highly ideological or spatial fashion, a small number of votes may have been subject to strategic behavior that related to parliamentary rules that inhibited discipline within the governing coalition. The French prime minister and the members of the cabinet were chosen from the Assembly membership. However, a vote against the government would not cause it to fall unless those voting against were an absolute majority of the membership. Thus, members of the governing coalition could cause a policy failure but not a government failure if their votes were strategically allocated. Moreover, one could normally vote down one government and hope to become a Cabinet minister in the next without fear of dissolution and the need to run for reelection. No dissolution was permitted in the first 18 months of a new parliament; afterwards, two absolute majority votes on confidence or censure motions needed to occur within an 18 month period before the Assemblé could be dissolved. Ministers and prospective ministers did not risk losing their parliamentary seats. Thus, personal ambition could drive strategic voting by some members. If deputies use personal ambition rather than ideology to motivate their choices on matters that directly affect control over executive power, we would expect these votes not to correspond well to the spatial model. In addition, strategic alliances to remove cabinets may result in systematic violations of the probabilistic spatial model and its error assumptions, such as extreme left and extreme right-wing parties voting together against a centrist government. Moreover if, as MacRae (1967) suggests, deputies 
with certain characteristics (so-called "ministrables") are more likely to vote strategically than others, i.i.d. assumptions are violated. ${ }^{3}$

Poole’s (2000) optimal classification method does not rely on assumptions about errors to uncover metric information from binary roll-call data. The optimal classification method seeks to find ideal points for legislators and separating hyperplanes for roll calls such that the number of classification errors is minimized. A classification error for a legislator on a roll call occurs when the legislator's ideal point is such that his or her vote is inconsistent with the separating hyperplane for the roll call. This procedure is highly robust to the stochastic nature of the data. Note that for optimal classification all errors are weighted equally. No single vote decision is likely to make a large difference in an estimate. In contrast, the parametric methods will adjust estimates based on the most serious errors, such as Rightists voting with the Communists against increased expenditures for colonial wars, which may well be the result of a strategic calculus to overthrow a centrist cabinet.

There is, of course, a price to be paid for using the non-parametric method. Metric information about ideal point locations and separating hyperplanes cannot be identified. In one dimension, this problem is a serious one. Only a rank order of legislator ideal points (and roll call cutting points) can be recovered. Two adjacent legislators in the rank order might have ideal points that are very close together or very distant. How does optimal classification recover metric

${ }^{3}$ On the other hand, Poole and Rosenthal (1997, chapters 2, 7) show how some forms of strategic voting will not affect the estimation of ideal points in the spatial model. Their illustrations pertain to binary agenda voting. In contrast, we are concerned with systematic deviations from spatial voting induced by personal ambition. 
information in more than one dimension? The two dimensional case illustrates the basic answer. If there is not much error to voting and we have many unique separating hyperplanes from the roll calls, each legislator's ideal point will typically be pinned down to a small cell generated by the intersections of hyperplanes. This cell does not generate a precise point estimate (Poole's method picks a point in the cell), but if the cells are small, the imprecision is small. Moreover, as Londregan (1999) has shown, any roll call method, including a parametric one, will suffer from this imprecision because of the coarseness or granularity of roll call data. In practice, the coarseness of the data does not appear to be problematic for the non-parametric method in the two-dimensional case. As we will demonstrate in the following analysis, the optimal classification method is able to produce plausible and interesting results in a situation where the parametric NOMINATE method fails.

\section{Data}

This report is very much a tribute to Duncan MacRae, Jr., who produced seminal research in roll call analysis. We use the data he assembled for his award winning, Parliament, Parties, and Society in France 1946-1958 (1967). ${ }^{4}$ MacRae’s book covered the turbulent Fourth Republic, often viewed as an indecisive and ineffective compromise constructed when democracy was restored after World War II. ${ }^{5}$ The Republic was cashiered by what was, for all purposes, a coup d'etat on May 13, 1958, produced by military and settler elements in Algeria. MacRae's sample

\footnotetext{
${ }^{4}$ The book won the 1968 APSA Woodrow Wilson Foundation Award, for the best book published on government, politics or international affairs.

${ }^{5}$ See, Leuthy (1955). See also Wood $(1964,1973)$ for other analyses of roll-call voting.
} 
of Fourth Republic roll calls consists of two parts. ${ }^{6}$ The first part consists of all 739 roll calls mentioned in L'Année Politique. Sampling in this way is roughly similar to constructing a sample for Congress using only “key” votes reported in Congressional Quarterly Weekly. L’Année Politique includes important votes, such as investitures, confidence votes, important budget votes, and other policy votes. The second part is a random sample of 50 votes per legislature from the remainder of all roll call votes.

Following Poole and Rosenthal (1997), we exclude all roll calls with fewer than $2.5 \%$ of those voting on the minority side. This reduces the sample from 889 to 855 votes, which is exactly one-tenth of the total of 8550 roll calls taken during the three legislatures of the Fourth Republic. The sample includes votes on topics such as NATO, the European Defense Community, Algeria, Indo-China, Italy treaty, Paris accords, military budget, atomic energy development, labor strike regulations, taxes, public health, Parisian transportation, colliery schools, National Assembly reform, agriculture, land reform, fiscal reform, inflation, salary scales, and amnesty. It includes a total of 33 votes to invest a new prime minister, and 136 votes of confidence. To check if our results are strongly influenced by the entire sample being heavily weighted by the L'Année Politique votes, we will report separately on results for the random sample. We exclude all deputies with fewer than 25 votes, which leaves a total of 1149 deputies.

${ }^{6}$ See MacRae (1964, Appendix A) for more detail. 
Abstentions of any form are disregarded. ${ }^{7}$ One overall characteristic of the roll calls is strikingly similar to that for the United State Congress; the average majority is a little under two-thirds. ${ }^{8}$

The data contains coding for the political party (technically, parliamentary group) of each deputy. In ouranalysis, we combine, in a straightforward manner, some of these codes. The major party groups include Communists, Socialists, Radicals ${ }^{9}$ (and UDSR), MRP (Christian Democrats), a collection of parties grouped as Right, ${ }^{10}$ and the Gaullists. ${ }^{11}$ Basic to the Communist-Socialist split was a pro-anti Soviet split. The Socialists diverged from the Radicals on issues of state ownership and intervention in the economy. In distinction to the Right, the Radicals were historically anti-clerical. Two parties, the MRP and the Gaullists had origins in the Resistance. Both, particularly the MRP, had some affinity for social democracy. The two parties differed sharply over working within the Fourth Republic institutions and over European unification. The Poujadists were a "Populist”, "flash” party that arose for the 1956 elections and vanished after De Gaulle came to power in 1958.

${ }^{7}$ In contrast, MacRae (1967) treats abstentions as equivalent to either No or Yes votes , based on pre-scaling adjustments. Abstentions constitute only 3.5\% of all valid votes in the sample.

${ }^{8} 62.3 \%$ in the first legislature, $64.4 \%$ in the second, $66.6 \%$ in the third legislature.

${ }^{9}$ The Radicals were "radical” only in a historical sense.

${ }^{10}$ The Right includes Parti Républicain de la Liberté, Républicains Indépendants, Indépendants, Paysans, Indépendants d’Outremer, Indépendants Paysans, Paysan, IPAS.

${ }^{11}$ The Gaullists include RPF, URAS, and ARS. 


\section{Analysis}

We fit three different spatial models to the data. The three nested models make different assumptions about the stability of deputy ideal points. First, we estimate a pooled model, which assumes that deputies who serve in more than one legislature hold constant ideal points during the entire Fourth Republic. The model thus estimates one ideal point for each deputy who served. There are 234 deputies present in all three legislatures and an additional 288 deputies who voted in two of the three legislatures. ${ }^{12}$ A total of 627 deputies belonged to only one of the three legislatures.

Second, we estimate a party-switcher model that nests the pooled model. The partyswitcher model assumes that only those deputies that remain loyal in their party affiliation have constant ideal points over time. This model takes into account that deputies who switch parties may shift their voting behavior accordingly. We find 202 deputies that changed party affiliation at least once, with 57 shifting their allegiance multiple times. ${ }^{13}$ The voting records of partyswitchers are broken up following these alterations in party affiliation. The party-switcher model thus estimates multiple ideal points for those deputies who switched parties.

12124 in both the $1^{\text {st }}$ and $2^{\text {nd }}, 116$ in the $2^{\text {nd }}$ and $3^{\text {rd }}$, and 48 in the $1^{\text {st }}$ and $3^{\text {rd }}$.

${ }^{13}$ MacRae assigned party codes for each individual roll call. We are therefore able to identify exactly when deputies decided to change their party affiliation. We include only changes within the major party categories given in the text. Thus, we do not treat as switches changes between party groups we identify as "Right”. We only count alterations if these endured for at least 25 votes. We do treat deputies who become unaffiliated with any party as switching. 
Third, the legislature-specific model relaxes the assumptions underlying the partyswitcher model further by assuming that deputies may also shift their ideal points following legislative elections. ${ }^{14}$ Elections caused significant shifts in both the individual and partisan composition of the legislatures. Most significantly, the Gaullists had zero seats in the first legislature but emerged as the largest party in the second legislature (117) and then lost dramatically in the ensuing elections (21 seats in the third legislature). Moreover, the issues on the agenda changed considerably between 1946 and 1958. In particular, the concerns posed by the Algerian war became more prominent in the later stages of the $4^{\text {th }}$ Republic. If such shifts in the substantive agenda in the Parliament and in party organizations led to shifts in the structure of ideological conflict, these legislature-specific models should fit the data better than models that assume continuity in legislator ideal points across legislatures.

We estimate each model with the optimal classification algorithm of Poole (2000) and the W-NOMINATE method of Poole and Rosenthal (1997). For data from the first 100 United States Congresses, the W-NOMINATE results are highly similar to the results from the Heckman-Snyder method (Poole and Rosenthal, 1997). Thus, we take W-NOMINATE as illustrative of a parametric method. Before comparing the estimated ideal points produced by the models, we discuss the fit and dimensionality.

\section{Fit and Dimensionality}

Table 1 summarizes the overall fit of the spatial models as estimated by the non-parametric Optimal Classification (OC) and W-NOMINATE (NOM) algorithms. The table shows results for estimated one, two, and three-dimensional models. As summary statistics, we present the

\footnotetext{
${ }^{14}$ The sample of vote choices is identical for all three models.
} 
classification percentages, and the Average Proportion Reductions in Error (APRE). The APRE denotes the extent to which the spatial model better accounts for observed vote choices than a model that simply predicts that each deputy always votes with the side in the majority on each roll call. ${ }^{15}$ The classification percentages for OC are generally more than $2 \%$ and sometimes close to 3\% higher than for W-NOMINATE. This difference between the two methods is a little larger than for Congress (Poole 2000). We should stress, however, that W-NOMINATE does not maximize classification. ${ }^{16}$

\section{TABLE ONE ABOUT HERE}

The results in table 1 demonstrate that a stable two-dimensional spatial configuration explains deputies' vote choices in the $4^{\text {th }}$ Republic extraordinarily well. Fixing ideal points in a twodimensional space throughout the 12-year duration of the Republic successfully accounts for 96.2\% of all vote choices. For our data, a third dimension has little explanatory value. Whereas introducing a second dimension reduces the proportion of errors by about $10 \%$, a third dimension ads only $2.5 \%$ to the APRE. ${ }^{17}$

$15 A P R E=\frac{\sum_{j=1}^{\mathrm{n}}(\text { Minority Vote }- \text { Classification Errors }) \mathrm{j}}{\sum_{j=1}^{\mathrm{n}}(\text { Minority Vote })_{\mathrm{j}}}$

${ }^{16}$ The classification of the three-dimensional NOMINATE model in three dimensions is higher for the pooled model than the party-switcher model. Such an apparent anomaly can readily occur when the classification is high, because NOMINATE is a (pseudo)-maximum likelihood algorithm that does not maximize classification.

${ }^{17}$ Negligible additions to fit were provided by considering four or more dimensions. 
Our two-dimensional fit is extremely high not only in absolute terms but also from a comparative perspective. For example, Poole (2000) reports that optimal classification for the United States Senate for the period of our study is about $85 \%$ in one dimension with another $5 \%$ added by a second dimension.

In comparing the fit of the three nested models we should take into account that the most restrictive (Pooled) model estimates only 1149 ideal points (one for each deputy), whereas the least restrictive (Legislature-specific) model estimates an additional 915 ideal points to account for shifts in party allegiance and legislatures. The results show that both allowing deputies to shift their ideal points following changes in party affiliation and (in addition) following elections leads to a modest improvement in the ability of the model to classify observed votes correctly. In two dimensions, party switching leads to a $0.4 \%$ improvement over the pooled model. The legislature-specific model adds another $0.4 \%$ over party switching. Thus, party switching gives a bigger bang for the parameter since it requires only 265 additional parameters to be estimated, whereas the further assumption that the ideological structure is legislature specific requires 648 extra parameters (ideal points).

The gain in classification from allowing deputies to change their ideal points following elections is thus very small considering the number of additional parameters. ${ }^{18}$ This indicates that although turnover between legislatures was large, the basic dimensions of ideological conflict were remarkably stable from 1946 to 1958.

\footnotetext{
${ }^{18}$ We also estimated a model that assumes deputies alter ideal points only following elections (not after party switches). In two dimensions, this model classifies $96.9 \%$ correctly, with an APRE of 91.3. The model estimates 1891 ideal points.
} 


\section{Comparison of the Methods}

Figure 1 presents the estimated deputy ideal points from the party-switcher model. The points appear in a two-dimensional scatter plot that facilitates the substantive interpretation of the two main dimensions of conflict. ${ }^{19}$ Our substantive interpretation of the dimensions focuses on two orthogonal axes, one running from Northwest to Southeast, which we label Pro-Anti Regime, and another from Southwest to Northeast, which we label Left-Right. Communists, Poujadists, and Gaullists anchor the anti-regime pole, with a smattering of the Right. The Socialists, MRP, and many Radicals are pro-regime. (The governing coalitions, particularly at the beginning of the $4^{\text {th }}$ Republic, were typically based on these parties. We use the regime as a shorthand for a division over acceptance of the Fourth Republic's basic institutions, which were clearly rejected by the Communists and the Gaullists, Indeed, the Gaullists cashiered these institutions when they took power in 1958. The anti-regime pole also groups interests who were opposed to France's integration into European institutions, most notably the European Defense Community, which was torpedoed in 1954 by a negative vote in the Assemblé. The dimension, however, was more than both ends against the middle voting, since neither the Gaullists nor the Poujadists were extreme right on economic issues.) Most of the Right and some Radicals occupy intermediate positions. The Left-Right dimension runs from the Communists and Socialists on one end to the Right parties on the other pole. MRP, Radicals, Gaullists, and Poujadists occupy intermediate positions.

\footnotetext{
${ }^{19}$ To facilitate visualization, only those deputies who voted at least 100 times while they belonged to one of our seven main party groups are displayed.
} 
It should be emphasized that the dimensions that arise from scaling techniques such as OC or WNOM are abstractions. The computer algorithms are "double blind" in the sense that they have no information about the content of the roll calls or about the party affiliation or other characteristics of the legislators. Thus, there is no requirement that the substantive topics that fall on a dimension hang together in some logical sense. If there is, therefore, a large number of roll calls where the economic left and right vote together because they have a common interest in destabilizing the regime, those roll calls will lead the scaling techniques to identify an important second dimension in addition to the standard left-right split.

It is noteworthy that when the First Legislature is scaled separately, the Regime axis becomes the horizontal (first) dimension of the scaling. In contrast, for the Second and Third Legislatures, Left-Right is horizontal and the Regime becomes the second dimension. This reflects the relative frequency of Regime vs. Left-Right issues in the legislatures. However, as table 1 demonstrates, the basic space is stable —one general space can classify all the votes as well as one space per legislature. Legislatures simply differ in the relative frequencies of roll calls on the dimensions.

\section{[FIGURE ONE ABOUT HERE]}

Figure 2 is the equivalent of figure 1, but is based on a W-NOMINATE scaling rather than the non-parametric Optimal Classification method. We have applied an orthogonal Procrustes rotation to the deputy coordinates such that the two scalings are maximally comparable. ${ }^{20}$ The

\footnotetext{
${ }^{20}$ The rotation was applied to the W-NOMINATE results with the optimal classification coordinates as the target. The rotation procedure is based on Schonemann (1966) and performed by a FORTRAN program written by Keith Poole.
} 
Pearson R-Squares between the corresponding first and second dimensions are .83 and .88 respectively. These are low in comparison to similar exercises for Congress (Poole 2000). This indicates that the correspondence between the two methods is smaller than in Congress. A comparison between Optimal Classification and W-NOMINATE discloses important differences.

First, whereas the Optimal Classification coordinates show a relatively smooth distribution throughout the space, the W-NOMINATE coordinates are concentrated at or near the unit circle that defines the boundary of the space for the W-NOMINATE algorithm. In fact, one-third of the deputies are placed on the rim. ${ }^{21}$ This is largely because classification is high and there is little error to voting. In order to maximize the log-likelihood, W-NOMINATE will place a "perfect” (errorless) legislator as far from the roll call cutting lines as possible. Such a circular distribution of ideal points seems implausible. As we said in the methodological discussion, parametric techniques need error to identify ideal points. With low error and a relatively low number of votes, the rim problem is aggravated. Indeed, the proportion of deputies on the rim is higher when we analyze the legislatures separately. In comparison to $33 \%$ of the deputies on the rim in the party-switching W-NOMINATE estimation, $42 \%, 36 \%$, and $49 \%$ are on the rim in the separate scalings of the first, second, and third legislature respectively. Therefore, Optimal Classification is particularly advantageous when there are relatively few roll calls.

\footnotetext{
${ }^{21}$ More precisely, these are the deputies for whom the sum of squares of the coordinates exceeds 0.99. A deputy exactly on the rim would have a sum of squares of 1.0 . We use 0.99 as the cutoff, because the coordinates are only precise up to two decimals.
} 
Second, the W-NOMINATE results fail, unlike those for Optimal Classification, to fill the space, leaving the right side of the space open. We suspect that is because the Communists are more error free than the other deputies. On votes that oppose the Communists to others, the horizontal dimension in figure 2, these differences in error are accommodated by placing the Communists on or near the rim and all others in the center.

Third, the pro-anti regime axis, where Gaullists, Communists, and Poujadists, split off from other parties is less clear in the W-NOMINATE scaling.

Fourth, in separate plots (available from authors) for the second and third legislatures, there is an enormous gap between the Communists and all other parties in the W-NOMINATE results, less so in Optimal Classification. ${ }^{22}$ This again largely reflects the Communists voting in a disciplined and errorless way. ${ }^{23}$ W-NOMINATE captures the "perfectness" of the Communists by making them very distant from everyone else. The gap seems implausible, particularly on the left-right or economic dimension where the Socialists, particularly in the 1940s and 50s, shared goals of redistribution and public ownership with the Communists. This problem is less severe when the legislatures are pooled, again suggesting that OC is particularly beneficial with small datasets.

${ }^{22}$ Eliminating the Communists from the sample does not solve the problems with WNOMINATE. One is left with a large gap between the Socialists and all other members.

${ }^{23}$ The fact that the Communists do not all have exactly the same ideal point reflects variations in abstention. Each deputy's position is determined by placing the deputy relative to the cutting lines for the roll calls on which he or she in fact voted. As figure 3 show, the Communists are highly clustered. Overstriking prevents this pattern from being apparent in figures 1 and 2. 


\section{Party Discipline and the Spatial Model}

One might think that our results largely reflect an ability to correctly classify the Communists and other parties exhibiting discipline. This is not the case. Table 2 reports the classification of the two-dimensional model by party against the predictions from a "party-coherence" model. This model simply stipulates that each legislator votes with the majority of her party. For highly disciplined parties, both models are very successful in correctly predicting vote choices. For less disciplined parties, the spatial model is generally more successful than the party cohesion model. Overall, the two-dimensional spatial model classifies an additional $1 \%$ of all vote choices correctly, even though it needs fewer parameters (6272) than the party-cohesion model (6840, a parameter for each party on each roll call). The spatial model is also successful in classifying non-affiliated legislators for which the party-discipline thesis has no prediction. Moreover, the spatial model has a much tighter theoretical focus than does a party cohesion model. Party cohesion says nothing about which way a party will vote on a particular roll call. The spatial model says that party voting must obey a consistent relationship to how other parties vote, the relationship being defined by the location of the ideal points of the party members.

The Christian Democrats are the only party whose vote choices are explained slightly better by the party cohesion model. A centrist party in a two-dimensional spatial model has many opportunities to vote en bloc in a manner that is inconsistent with the constraints imposed by a low-dimensional spatial model. Theoretically, we need a six dimensional spatial model to account for the vote choices of seven perfectly disciplined parties. However, our results show that, overall, a two-dimensional spatial model better classifies the data than does a party coherence model. 
These points are further illustrated by figure 3 , which depicts the distribution of legislator ideal points on the first dimension by party. The figure demonstrates that the ideal points of legislators within parties are not all identical and that some parties overlap.

\section{Strategic Voting on Cabinets}

Strategic voting to undermine or support cabinets violates the spatial model and the error assumptions underlying the probabilistic variant of the spatial model. Since parametric methods depend strongly on these error assumptions to be met, parameter estimates may be affected by the presence of strategic voting. A very out-of-character vote can have a major impact on parametric methods. For example, say just one Right deputy voted with the Communists on a roll call where all others voted against. The optimal cutting line would be unaffected by this aberrant choice. In contrast, the cutting line for W-NOMINATE would move toward the Rightist's ideal point, in order to improve the likelihood for the roll call. Similarly, the Rightist's ideal point would be moved toward the center by W-NOMINATE where it might be unchanged in OC. The non-parametric variant is thus robust to the stochastic nature of the data and its estimates are less affected by the presence of voting “errors” caused by strategic voting.

In the remainder of this paper, we assume, therefore, that strategic voting on a few roll calls will not make an important difference to the OC methods. We then proceed to illustrate how the non-parametric method can be used to assess the extent and form of strategic voting in a legislature.

A first question is whether deputies vote strategically on motions of confidence and on motions of investiture of prime ministers? Table 3 helps to answer this question by breaking out the APREs from each legislature-specific scaling into four mutually exclusive and exhaustive categories: Investiture votes, Motions of confidence, Other L'Année Politique (important) votes, 
and Random Sample votes. If legislators routinely use non-ideological calculations in their votes on investitures and motions of confidence, we expect these types of votes to fit the spatial model less well than other roll calls.

The first column for each legislature shows the fit for a one-dimensional estimation, the second for two dimensions. A category with a high fit in one dimension thus includes roll calls that largely express divisions on the main dimension for that legislature. A category with a relatively low fit in a one-dimensional model but a high fit in two dimensions would largely consist of roll calls that tap the second dimension.

Table 3A has results for models that do not control for party switching. Table 3B shows the results where deputies are allowed to shift their ideal point following a change in partisan adherence. The difference is important, because party-switches may be indicative of strategic behavior. . For obvious reasons, party switching has the least effect in the third legislature, which has the fewest votes, and the strongest effect in the pooled estimation

The results, clearest in the "Pooled" column, indicate that the impact of party switching most strongly impacts the fit of the model on investiture votes, and barely has an effect on the roll calls from the random sample. A possible explanation is that on investiture votes, parties put more pressure on their members to vote along party lines. If party-switchers adjust their ideal point towards the center of the party they are changing to, controlling for changes in party affiliation affects the fit of the model more on votes where parties are more cohesive. A complementary explanation is that dissatisfaction with the original party's position on issues directly affecting cabinet performance caused most party-switchers to leave. As a result, they may not change their voting behavior on general issues much, but do alter their choices on roll calls that involve the fate of cabinets. 


\section{TABLE 3 ABOUT HERE}

All roll call voting was highly ideological with important votes that led to the birth and death of cabinets being especially ideological. The votes randomly selected by MacRae fit the model only slightly less well in the first and third legislatures than do important "Other" votes that do not involve the cabinet. In the second legislature, however, the random votes fit especially well. In two dimensions, investiture and confidence votes generally fit better than other votes. There is little evidence that suggests systematic strategic voting on roll calls that involved the formation or breakdown of cabinets, at least not of the gamesmanship kind that contrasts with the spatial model.

On the other hand, the existence of the Fourth Republic may have itself been an important source of consistent, spatially ideological voting. We earlier identified the major conflict in the first legislature not as a standard left-right dimension but as a pro-anti regime dimension. This interpretation is reinforced by noting that investiture and confidence votes in the first legislature, fit exceptionally well on the regime (first) dimension. The story for the second and third legislatures is somewhat different. Investiture votes are mainly along the leftright dimension while confidence votes are more along the regime dimension. Cabinets appear to have been chosen in terms of standard left-right policy splits but then cashiered in attacks on the regime. (The low first dimension PRE of 78.4 for third legislature investitures reflects an outlier, the failed investiture vote for Mollet on October 28, 1957. Without this vote, the APRE is 86.0).

Confidence votes in the second legislature are the exception to all this. The twodimensional model explains these votes (somewhat) less well than any other category of votes. Perhaps the behavior of deputies on these votes has important strategic origins, for example caused by the opportunistic behavior of ministrables. MacRae (1967) operationalizes a 
ministrable as a deputy who was a member of a cabinet at some point in the Republic, but is not a member of a cabinet at the time of a particular motion of confidence. Such deputies may have an interest in voting against cabinets not because of their ideological positions, but in order to increase the probability of obtaining a prestigious cabinet position. To test this hypothesis, we ran a probit analysis on a pooled data set with all 51 motions of confidence brought before the second legislature. Besides the ministrable variable, we included a dummy variable that indicates membership in a cabinet, and the first and second dimension coordinates for deputies. ${ }^{24}$

The coefficient on the "ministrable" variable is significant in the expected direction (-.12, $\mathrm{z}=-2.5, \mathrm{p}=.014$ ), indicating that ministrables were indeed more likely to vote against matters of confidence than were other deputies. ${ }^{25}$ This effect, however, is small. If a deputy were otherwise estimated to have a probability of 0.50 of voting against the government, being a ministrable would lower this probability only to 0.45 . Indeed, if we run the same model on the individual votes of confidence, we find only three votes of confidence, two on Faure and one on Mendès-France ${ }^{26}$ where the variable reaches a $5 \%$ significance level. ${ }^{27}$ Of these, only in one

${ }^{24}$ In order to capture polarity, all coordinates were interacted with a dummy for each roll call. ${ }^{25}$ Panel-corrected standard errors. Log likelihood $=-8571.2103$, Pseudo $R^{2}=0.55$. Coefficient on the cabinet dummy is .78 ( $\mathrm{z}=10.1, \mathrm{p}=.000)$. Thus, cabinet members were especially likely to support the cabinets. The positive effect of support from current ministers was far greater than the negative effect from "ministrables".

${ }^{26}$ Scrutin numbers 696,771 , and 2821 . The coefficients on these votes exceeded the coefficient in the ministrable variable in the pooled analysis: $(-4,18(\mathrm{p}=.000) ;-2,21(\mathrm{p}=.027) ;-2,28$ $(\mathrm{p}=.022))$. 
case, Faure, was confidence denied to the government. Thus, we can only find one case in which the fate of a cabinet was partly determined by opportunistic behavior from ministrables: the first Faure cabinet. $^{28}$ On this roll call, several Radicals that had been cabinet members under Mendès and a few ministrables from the MRP and the Right broke party lines in order to undermine the cabinet. $^{29}$

\section{Both Ends Against the Middle}

The fact that confidence votes fall mainly along the regime dimension suggests that government instability arose simply because both ends voted against the middle within a standard onedimensional left-right perspective. To test this, we estimated a one-dimensional non-parametric model with two cutpoints, using a program created by Keith Poole. Whereas standard Euclidean models of voting predict the existence of a single cutpoint on each roll call that splits legislators into "left" and "right" camps, a two-cutpoint model allows both left and right extremists to vote against the center. In the French context, it allows the Right to vote with the Communists. Indeed, the Right failed to rally to Mollet when the Communists withdrew support for his government in 1957, brought down Bourgès-Maunoury over Algeria in September, 1957, failed to invest Mollet in October, and brought down Gaillard, again over Algeria, in April of 1958, all in the Third legislature and all in conjunction with the Communists.

\footnotetext{
${ }^{27}$ Note that coefficients could not be estimated for those votes that were explained perfectly by the ideological variables.

${ }^{28}$ The first dimension coordinates are insignificant, but the second dimension coordinates are highly significant: $3.98(\mathrm{z}=15.48, \mathrm{p}=.000)$.

${ }^{29}$ This case was also identified by MacRae, p. 199.
} 
Not surprisingly, a two-cutpoint model failed to improve results very much in the first legislature where votes were already mainly along a regime dimension, with the Right out of place and adjacent to the Communists. One-dimensional classification with a two-cutpoint model generates an increase over that from a one cutpoint model only from $95.1 \%$ to $96.2 \%$. In the second legislature, the improvement is somewhat greater, from $91.6 \%$ to $93.3 \%$ whereas a twodimensional model classifies at $95.7 \%$. The reason that both ends against the middle fails to fully capture anti-regime voting in the second legislature is that the anti-regime Gaullists were a center party on the left-right dimension, where most of the votes took place. Voting against the regime thus involved the Communists, the Right, and a party that was relatively in the middle. Only in the third legislature, can attacks on the regime be truly viewed as "both ends against the middle.” Classification increases from $93.7 \%$ to $97.0 \%$. This is nearly as much as the twodimensional classification percentage of $97.6 \%$. The result is all the more impressive in that there is considerably less parameter fitting in a two-cutpoint, one-dimensional model than in a standard two-dimensional model. In the two-cutpoint model, one simply adds one parameter per roll call. In a two-dimensional model, one not only adds one parameter per roll call but one parameter per deputy. Since the third legislature includes 599 deputies but, as a result of the brief life of the legislature, only 163 roll calls, the two-cutpoint model is very parsimonious compared to the two-dimensional model and allows for a systematic form of strategic behavior. The extreme left and right voting together against the center is common in Europe. For example, in the European Parliament, the second dimension consists of conflict over European integration, which both the extreme left and right disapprove (Noury, 2002). We thus suspect the twocutpoint model will find broader use. 


\section{Conclusion}

There are three reasons why Poole's non-parametric method better captures the ideological divisions in the French Fourth Republic than the more common parametric approaches. First, the varying degrees of cohesiveness of French parties strongly violate the i.i.d. assumption about the

distribution of errors. Second, the absence of substantial errors in the voting behavior of deputies makes identification of parametric models problematical. Third, the optimal classification algorithm is more robust to both-ends-against-the-middle and other forms of strategic voting, which violates both the assumptions about the distribution of errors and the utility function underlying parametric models.

We believe that future studies should consider these points when analyzing roll call voting in settings other than the United States Congress. Most legislatures have stronger party systems than Congress, which may lead to both severe violations of the i.i.d. assumption and near perfect ideological voting. Moreover, in parliamentary systems legislators vote not just on policy proposals but also on the future of those who hold executive power. This may lead to systematic strategic behavior, such as that captured by "both-ends-against-the-middle voting." Poole's non-parametric methods provide a viable alternative when the assumptions underlying parametric models are violated. 


\section{References}

Carey, John M. 2003. “Discipline, Accountability, and Legislative Voting in Latin America.” Comparative Politics 35(2):191-211.

Clinton, Joshua D., Simon Jackman, and Douglas Rivers. 2001. “The Statistical Analysis of Roll-Call Voting.” Typescript Stanford University.

Clinton, Joshua D. and Adam Meirowitz. 2001. “Agenda Constrained Legislator Ideal Points and the Spatial Voting Model.” Political Analysis 9(3): 242-60.

Desposato, Scott. 2003 "Parties for Rent? Careerism, Ideology, and Party Switching in Brazil's Chamber of Deputies." Typescript University of Arizona.

Diermeier, Daniel and Randolph Stevenson. 2000. "Cabinet Terminations and Critical Events.” American Political Science Review 94(3): 627-40.

Enelow, James M. and Melvin J. Hinich. 1984. The Spatial Theory of Voting: an Introduction. New York: Cambridge University Press.

Heckman, James J. and James M. Snyder. 1997. "Linear Probability Models of the Demand for Attributes With an Empirical Application to Estimating the Preferences of Legislators.” Rand Journal of Economics, 28 (SI):142-189.

Hix, Simon. 2001. "Legislative Behaviour and Party Competition in the European Parliament: An Application of Nominate to the EU.” Journal of Common Market Studies 29(4): 66388.

Hix, Simon, Abdul Noury and Gerard Roland. 2002. “A ‘Normal’ Parliament?: Party Cohesion and Competition in the European Parliament 1979-2001.” Presented at the Public Choice Society Conference San Diego 21-23 March. 
Huber, John D. and Cecilia Martinez-Gallardo. 2002. "Cabinet Instability and the Accumulation of Experience in the Cabinet: The French Fourth and Fifth Republics in Comparative Perspective.” Typescript Columbia University.

Jackman, Simon. 2001. "Estimating Ideological Locations in Australian Political Institutions,” Presented to the annual meeting of the Australasian Political Studies Association, Brisbane, Australia, September 2001.

Janda, Kenneth. 1980 Political Parties: A Cross-National Survey. New York: The Free Press. Jenkins, Jeffrey. 1999. "Examining the Bonding Effects of Party: A Comparative Analysis of Roll-Call Voting in the U.S. and Confederate Houses." American Journal of Political Science 43(4): 1144-65.

Kiewiet, D. Roderick and Mikhail G. Myagkov. 1996. "Czar Rule in the Russian Congress of Peoples Deputies?" Legislative Studies Quarterly, 21(1): 3-40.

Leuthy, Herbert. 1955. France Against Herself: A Perceptive Study of France’s Past, Her Politics, and Her Unending Crises. New York City: Praeger.

Londregan, John. 1999. “Estimating Legislators’ Preferred Points.” Political Analysis 8(1)35-56. 2000. Legislative Institutions and Ideology in Chile. Cambridge: Cambridge University Press.

Mercik, J.W., and M. Mazurkiewicz. 1997. "Dimensional Analysis of Parliamentary Decisions.” Technical University of Wroclaw, Technical Report.

MacRae, Duncan, Jr. 1967. Parliament, Parties, and Society in France 1946-1958. New York: St. Martin’s Press.

McCarty, Nolan, Keith T. Poole and Howard Rosenthal (2001). "The Hunt for Party Discipline in Congress.” American Political Science Review 75(2): 673-87. 
McKelvey, Richard and Rosenthal, Howard. 1978. "N-Person Cooperative Game Theory and Spatial Models of Politics: Empirical Analysis of Electoral Coalitions in France." In: Peter Ordeshook (ed.) Game Theory and Political Science. New York: NYU Press, Morgenstern, Scott. 2003. Patterns of Legislative Politics: Roll Call Voting in Latin America and the United States. Cambridge University Press (coming December 2003)

Noury, Abdul G. (2002) "Ideology, Nationality and Euro-Parliamentarians" European Union Politics 3(1): 33-58.

Noury, Abdul G. and Elena Mielcova. 1997. "Roll Call Voting in a Multi-Party Parliament: The Case of the Czech Parliament," Working Paper, Free University of Brussels, Belgium.

Poole, Keith T. 2000. “Non-Parametric Unfolding of Binary Choice Data.” Political Analysis, 8(3): 211-32. 2001. "The Geometry of Multidimensional Quadratic Utility in Models of Parliamentary Roll Call Voting." Political Analysis, 9(3): 211-226.

Poole, Keith T. and Howard Rosenthal. 1985. "A Spatial Model for Legislative Roll Call Analysis." American Journal of Political Science, 29(2): 357-384 1991. "Patterns of Congressional Voting." American Journal of Political Science, 35(1): 228-278.

1997. Congress: A Political-Economic History of Roll Call Voting. New York: Oxford University Press 2001. "D-NOMINATE after 10 Years: A Comparative Update to Congress " Legislative Studies Quarterly, 26(1): 5-29.

Riker, William 1959. “A Test of the Adequacy of the Power Index.” Behavioral Sciences 4(2): 120-31. 
Schickler, Eric. 2000. “Institutional Change in the House of Representatives, 1867-1998: A Test of Partisan and Ideological Power Balance Models.” American Political Science Review 94 (2): 269-88.

Schonhardt-Bailey, Cheryl. 2003 "Ideology, Party and Interests in the British Parliament of 1841-1847", British Journal of Political Science 33(4) (October 2003)

Voeten, Erik (2000). “Clashes in the Assembly.” International Organization 54(2): 185-216.

Wood, David M. (1964). “Issue Dimensions in a Multi-Party System: The French National Assembly and European Unification.” Midwest Journal of Political Science 8(3): 25576.

(1973). “ Responsibility for the Fall of Cabinets in the French Fourth Republic, 1951-55.” American Journal of Political Science 17(4): 767-80 
Table 1. Fit Statistics For Optimal Classification

\begin{tabular}{|c|c|c|c|c|c|c|c|}
\hline & & \multicolumn{2}{|c|}{ Pooled } & \multicolumn{2}{|c|}{ Party Switchers } & \multicolumn{2}{|c|}{$\begin{array}{c}\text { Legislature } \\
\text { Specific }\end{array}$} \\
\hline \multicolumn{2}{|c|}{ Number of Ideal Points } & \multicolumn{2}{|c|}{1149} & \multicolumn{2}{|c|}{1416} & \multicolumn{2}{|c|}{2064} \\
\hline & & $\mathrm{OC}$ & NOM & OC & NOM & OC & $\mathrm{NOM}$ \\
\hline \multirow[t]{2}{*}{1 Dimension } & Class. \% & 92.4 & 89.7 & 93.2 & 90.6 & 93.6 & 91.4 \\
\hline & APRE & 78.8 & 71.2 & 81.0 & 73.8 & 82.0 & 75.3 \\
\hline \multirow[t]{2}{*}{2 Dimensions } & Class. $\%$ & 96.2 & 93.6 & 96.6 & 93.8 & 97.0 & 94.5 \\
\hline & APRE & 89.3 & 82.0 & 90.5 & 82.8 & 91.6 & 84.6 \\
\hline \multirow[t]{2}{*}{3 Dimensions } & Class. $\%$ & 97.0 & 95.3 & 97.5 & 94.5 & 98.2 & 95.7 \\
\hline & APRE & 91.8 & 86.8 & 93.0 & 84.6 & 94.7 & 87.5 \\
\hline \multicolumn{2}{|c|}{ APRE2-APRE1 ${ }^{\mathrm{a}}$} & 10.5 & 10.8 & 9.5 & 9.0 & 9.6 & 9.3 \\
\hline \multicolumn{2}{|c|}{ APRE3-APRE2 ${ }^{\mathrm{b}}$} & 2.5 & 4.8 & 2.5 & 1.8 & 3.1 & 2.9 \\
\hline
\end{tabular}

\footnotetext{
${ }^{\mathrm{a}}$ Difference between APRE in two-dimensional model and one-dimensional model.

${ }^{\mathrm{b}}$ Difference between APRE in three-dimensional model and two-dimensional model.
} 
Table 2. Classification Success of Two-Dimensional Spatial Model versus Party Coherence Model

\begin{tabular}{l|cc|c}
\hline Party & $\begin{array}{c}\text { Party } \\
\text { Coherence } \\
\text { Model }\end{array}$ & $\begin{array}{c}\text { 2-Dimensional } \\
\text { Optimal } \\
\text { Classification }\end{array}$ & \% of Votes Cast \\
\hline Communist & 99.9 & 100.0 & 23.1 \\
Socialist & 99.0 & 99.1 & 17.5 \\
Radical and UDSR & 89.0 & 90.9 & 12.7 \\
Christian Democrat & 97.8 & 97.0 & 18.6 \\
Right (Modéré) & 90.5 & 94.4 & 14.8 \\
Gaullist & 91.6 & 94.7 & 7.4 \\
Poujadist & 98.9 & 99.4 & 1.2 \\
Others and Not Affiliated & N.A. & 94.4 & 4.7 \\
\hline Total (Excluding Others & 95.7 & 96.7 & 100 \\
and Not Affiliated) & & & \\
\hline All calculations are based & & & \\
\hline
\end{tabular}

Note: All calculations are based on the data used for the party-switcher model. 
Table 3: Mean PRE by Roll-call Type for One- and Two-Dimensional Optimal 3A: No Party-Switching

\section{Classification}

\begin{tabular}{|c|c|c|c|c|c|c|c|c|c|c|c|c|}
\hline \multirow{3}{*}{ Type } & \multicolumn{3}{|c|}{$1^{\text {st }}$ Legislature } & \multicolumn{3}{|c|}{$2^{\text {nd }}$ Legislature } & \multicolumn{3}{|c|}{$3^{\text {rd }}$ Legislature } & \multicolumn{3}{|c|}{ Pooled } \\
\hline & 1D & 2D & $\mathbf{N}$ & 1D & 2D & $\mathbf{N}$ & 1D & $2 D$ & $\mathbf{N}$ & 1D & $2 D$ & $\mathbf{N}$ \\
\hline & Reg & L-R & & L-R & Reg & & L-R & Reg & & & & \\
\hline Investiture & 90.7 & 91.0 & 13 & 89.0 & 94.6 & 13 & 79.7 & 94.1 & 7 & 84.3 & 91.5 & 33 \\
\hline Confidence & 91.2 & 95.5 & 44 & 73.8 & 86.7 & 51 & 81.9 & 93.3 & 41 & 76.6 & 88.5 & 136 \\
\hline Random & 77.8 & 89.9 & 44 & 88.9 & 94.3 & 47 & 80.3 & 90.9 & 45 & 81.2 & 88.9 & 136 \\
\hline Other & 83.2 & 92.7 & 245 & 74.8 & 87.4 & 235 & 84.2 & 92.0 & 70 & 78.0 & 88.2 & 550 \\
\hline
\end{tabular}

3B: Party Switching

\begin{tabular}{l|cccccccccccc}
\hline \multirow{1}{*}{ Type } & \multicolumn{1}{|c}{$\mathbf{1}^{\text {st }}$ Legislature } & \multicolumn{2}{c}{$\mathbf{2}^{\text {nd }}$ Legislature } & \multicolumn{3}{c}{$\mathbf{3}^{\text {rd }}$ Legislature } & \multicolumn{3}{c}{ Pooled } \\
& 1D & 2D & N & 1D & 2D & N & 1D & 2D & N & 1D & 2D & \\
& Reg & L-R & & L-R & Reg & & L-R & Reg & & & & \\
\hline Investiture & 91.7 & 92.3 & 13 & 89.7 & 94.8 & 13 & 78.4 & 94.1 & 7 & 87.1 & 93.7 & 33 \\
Confidence & 92.6 & 96.4 & 44 & 74.4 & 87.4 & 51 & 83.3 & 93.5 & 41 & 79.9 & 90.0 & 136 \\
Random & 78.0 & 90.8 & 44 & 88.8 & 94.1 & 47 & 80.3 & 91.9 & 45 & 82.7 & 90.3 & 136 \\
Other & 84.1 & 93.3 & 245 & 75.2 & 87.6 & 235 & 84.1 & 92.2 & 70 & 79.7 & 89.6 & 550 \\
\hline
\end{tabular}

Note: Reg means that the dimension mostly corresponds to conflict over the regime, L-R that it mostly concerns Left-Right conflict. 
Figure 1: Legislator Coordinates, Optimal Classification

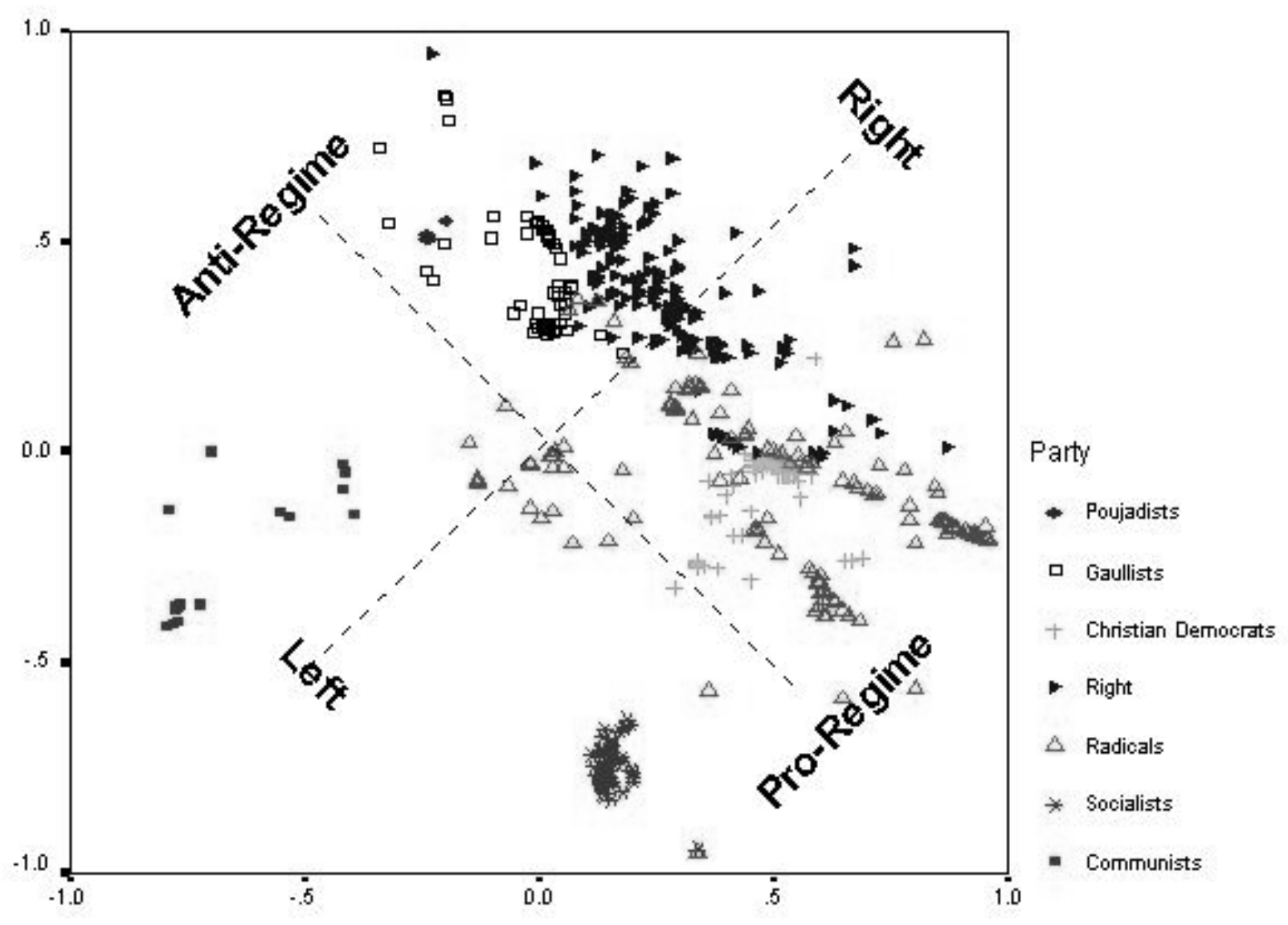


Figure 2: Legislator Coordinates, W-NOMINATE

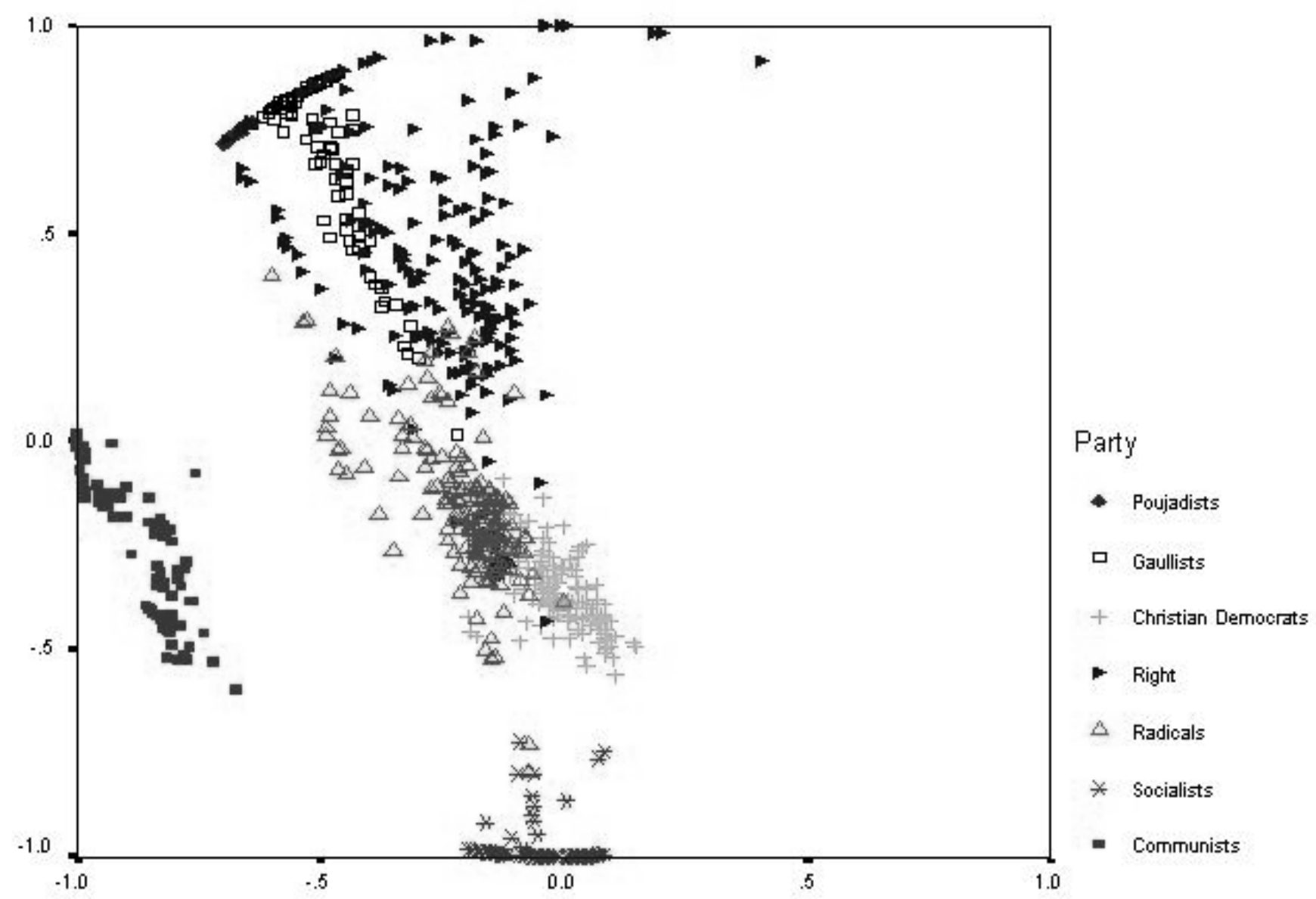




\section{Figure 3: Distribution of Legislators Along First Dimension by Party}

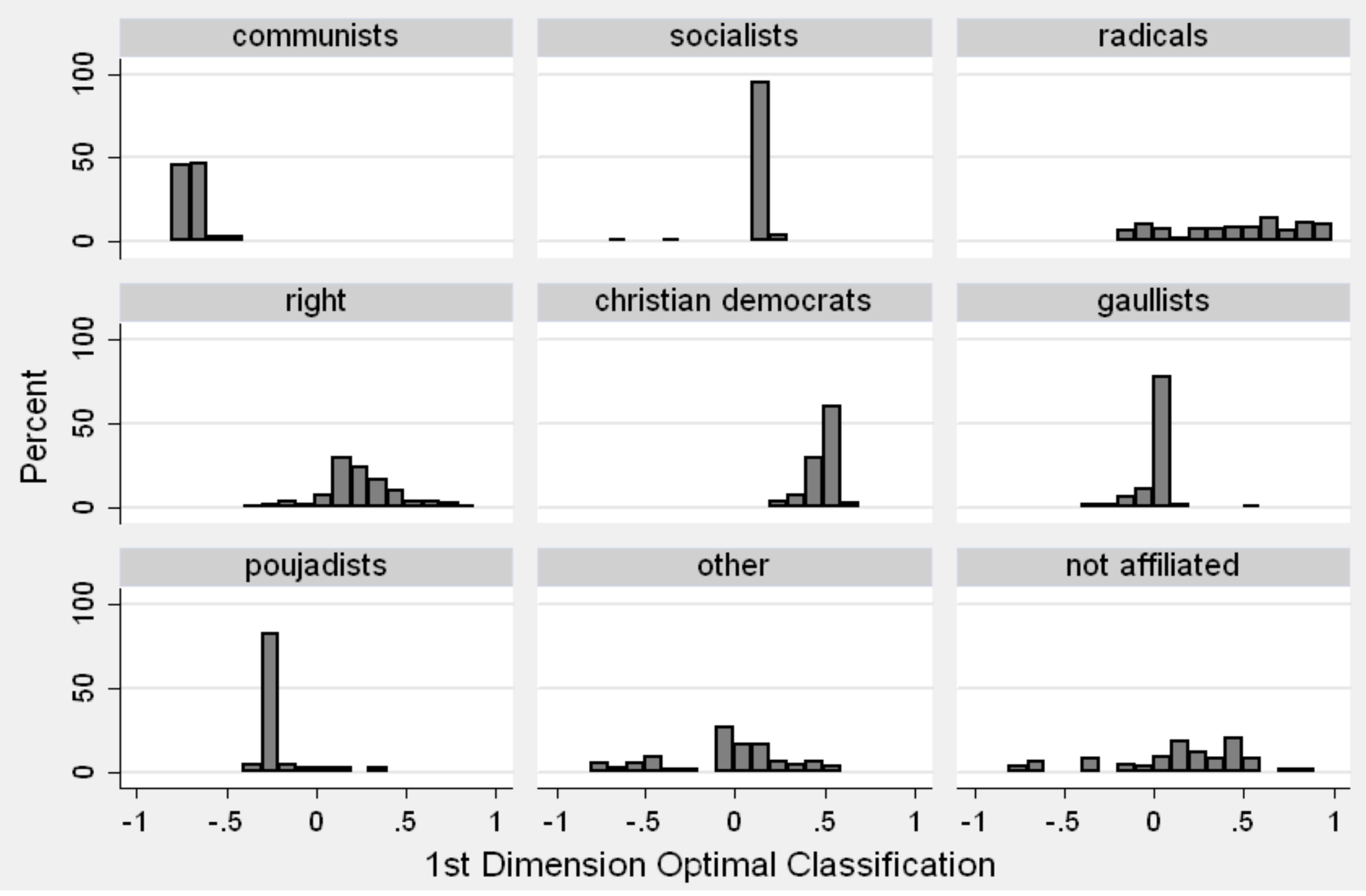

